\title{
Ação do óleo essencial de Citronela (Cymbopogon nardus L) sobre o patógeno Lasiodiplodia theobromae em cachos de videira cv. Itália
}

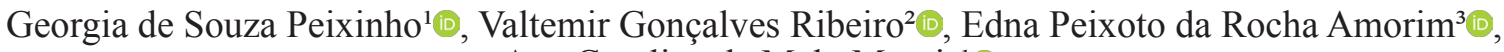 \\ Ana Caroline de Melo Morais ${ }^{1} \mathbb{D}$.
}

\begin{abstract}
${ }^{1}$ Doutoranda pelo programa de Pós-graduação em Proteção de Plantas, pela Universidade Federal de Alagoas (UFAL), Centro de Ciências Agrárias, Rio Largo, AL, Brasil, CEP 57080-000, ${ }^{2}$ Programa de Pós-graduação em Agronomia: Horticultura Irrigada (PPGHI), pela Universidade do Estado da Bahia (UNEB)/Departamento de Tecnologia e Ciências Sociais (DTCS), Juazeiro, BA, Brasil, CEP 48905-680, ${ }^{3}$ Universidade Federal de Alagoas, Centro de Ciências Agrárias/Departamento de Fitossanidade, Rio Largo, AL, Brasil, CEP 57080-000.
\end{abstract}

Endereço para correspondência: Ana Caroline de Melo Morais (moraiscaroline@live.com)

Data de chegada: 05/07/2018. Aceito para publicação em: 03/07/2019.

$10.1590 / 0100-5405 / 206511$

\section{RESUMO}

Peixinho, G.S.; Ribeiro, V.G.; Amorim, E.P.R.; Morais, A.C.M. Ação do óleo essencial de Citronela (Cymbopogon nardus L) sobre o patógeno Lasiodiplodia theobromae em cachos de videira cv. Itália. Summa Phytopathologica, v.45, n.4, p.428-431, 2019.

A presença de Lasiodiplodia theobromae (Podridão seca) em videiras implantadas em áreas irrigadas da região semiárida brasileira, tem mostrado elevada agressividade ao infectar várias partes das plantas. Os óleos essenciais têm apresentado eficiência no controle de doenças, tanto pela ação fungitóxica, inibindo o crescimento micelial e a germinação de esporos, além da presença de compostos eliciadores. Com isso, o presente trabalho teve por objetivo obter o controle de L. theobromae pela utilização do óleo de Citronela (Cymbopogon nardus $\mathrm{L}$ ) em diferentes dosagens. $\mathrm{O}$ crescimento micelial de $L$. theobromae foi analisado em placas de Petri contendo o meio batata-dextroseágar suplementado com o óleo essencial nas seguintes concentrações: $0 ; 0,25$; 0,$5 ; 1,0 ; 1,5$ e $2,0 \%$. Para avaliação do efeito direto do óleo essencial sobre o desenvolvimento da doença, os cachos de uva foram inoculados com o patógeno e, após 4 horas, aspergidos com soluções contendo as mesmas concentrações descritas anteriormente; posteriormente, com o objetivo de avaliar o potencial do óleo essencial no tratamento preventivo, os mesmos tratamentos foram aplicados em cachos de uva 4 horas antes da inoculação. O óleo de Citronela em todas as concentrações testadas foi capaz de inibir o crescimento micelial de L. theobromae em $100 \%$. No tratamento curativo, com relação a incidência, Citronela $0,25 \%$ reduziu $38 \%$ na infecção de bagas de cachos de uva inoculadas $\operatorname{com} L$. theobromae, sendo capaz de reduzir a severidade da doença em $56 \%$. No tratamento preventivo, o óleo de Citronela a $0,25 \%$ reduziu em $52 \%$ a infecção das bagas de uva cv. Itália, reduzindo a severidade da doença em $66,3 \%$. Sendo possível concluir que a concentração $0,25 \%$ foi a melhor dosagem testada para o controle da doença com o óleo essencial de Citronela.

Palavras-chave: controle alternativo, produtos naturais, podridão seca.

\section{ABSTRACT}

Peixinho, G.S.; Ribeiro, V.G.; Amorim, E.P.R.; Morais, A.C.M. Action of citronella (Cymbopogon nardus L) essential oil on the pathogen Lasiodiplodia theobromae in bunches of grapevine cv. 'Itália'. Summa Phytopathologica, v.45, n.4, p.428-431, 2019.

Presence of Lasiodiplodia theobromae (dry rot) in vines established in irrigated areas of the Brazilian semiarid region has shown to be highly aggressive when infecting several parts of the plants. Essential oils have shown efficiency in controlling diseases, both by the fungitoxic action, inhibiting mycelial growth and spore germination, and by the presence of eliciting compounds. Thus, the objective of this study was to obtain control of $L$. theobromae by using citronella oil (Cymbopogon nardus $\mathrm{L}$ ) at different levels. Mycelial growth of $L$. theobromae was analyzed in Petri dishes containing potato-dextrose-agar medium supplemented with essential oil at the following concentrations: $0 ; 0.25 ; 0.5 ; 1.0 ; 1.5$ and $2.0 \%$. To evaluate the direct effect of the essential oil on the development of the disease, grape bunches were inoculated with the pathogen and, after $4 \mathrm{~h}$, sprayed with solutions containing the same concentrations described above; subsequently, in order to evaluate the potential of the essential oil in the preventive treatment, the same treatments were applied in grape bunches 4 hours before inoculation. Citronella oil at all tested concentrations was capable of inhibiting the mycelial growth of L. theobromae by $100 \%$. For the healing treatment, considering incidence, $0.25 \%$ citronella reduced by $38 \%$ the infection in berries of grape bunches inoculated with $L$. theobromae and was capable of reducing the disease severity by $56 \%$. As regards the preventive treatment, $0.25 \%$ citronella oil reduced by $52 \%$ the infection in berries of grape bunches cv. 'Itália', reducing the disease severity by $66.3 \%$. These results lead to the conclusion that $0.25 \%$ was the best concentration tested for disease control with citronella essential oil.

Keywords: alternative control, natural products, dry rot.

Doenças causadas por fungo s são considerados como uma das principais causas de perdas na fase de armazenamento e comercialização de frutas tropicais. Dentre as enfermidades que acometem a videira, a podridão seca da uva (Lasiodiplodia theobromae (Pat.) Griffon e Maubl $($ Syn. $=$ Botryodiplodia theobromae $)$ merece atenção por tratar-se de uma doença que se expressa frequentemente na fase final de maturação, reduz a vida útil de prateleira, diminui a produção, desqualifica as frutas e aumenta os custos de produção, sendo o seu controle ainda um desafio (13).

A presença de L. theobromae em áreas irrigadas do trópico 
semiárido brasileiro - caracterizada por apresentar o microclima ideal para o seu desenvolvimento (13) - foi verificada nas culturas da mangueira, videira, goiabeira, laranjeira, coqueiro, tamareira, abacateiro, bananeira, limoeiro, maracujazeiro, sendo comumente conhecida como podridão seca ou morte descendente. Em todas as culturas o fungo mostrava-se muito agressivo infectando várias partes das plantas, causando diferentes sintomas nas plantas, desde a morte descendente ("dry-back") o cancro em raízes, caules e ramos, lesões em folhas, sementes, estacas e frutos, resultando na morte de mudas e enxertos (13).

O uso de defensivos químicos tem controlado doenças de plantas. Porém, o uso contínuo e indiscriminado desses produtos causa uma série de problemas ambientais e à saúde humana (13). A utilização de produtos naturais no controle de doenças de plantas representa um meio eficiente para a redução do uso de defensivos agrícolas (6).

Considerando o potencial de uso de produtos fitoterápicos e dos danos provocados por $L$. theobromae na viticultura, o presente trabalho teve como objetivo verificar o efeito do óleo de Citronela no controle in vitro de L. theobromae e no controle preventivo e curativo da podridão seca em cachos de uva.

Os experimentos foram conduzidos no laboratório de Fitopatologia, Centro de Ciências Agrárias (CECA) da Universidade Federal de Alagoas (UFAL), em Rio Largo.

Para a realização deste estudo, incorporou-se óleo essencial de Citronela (Cymbopogon nardus $\mathrm{L}$ ) ao meio de cultura batata-dextroseágar (BDA), fundente $\left(45-50{ }^{\circ} \mathrm{C}\right)$, vertido em placas de Petri de $9 \mathrm{~cm}$ de diâmetro, usando-se 6 placas para cada tratamento, o qual consistiu em diferentes dosagens do óleo $(0 ; 0,25 ; 0,5 ; 1,0 ; 1,5$ e $2,0 \%)$. Todos os tratamentos foram esterilizados em luz UV por 30 minutos antes de serem adicionados ao meio autoclavado (2).

No centro de cada placa foi depositado um disco de meio BDA, de $0,6 \mathrm{~cm}$ de diâmetro, contendo micélio, retirado das bordas da colônia do patógeno. Após a incubação por cinco dias à temperatura de 28 ${ }^{\circ} \mathrm{C}$ e fotoperíodo de 12 horas, foi determinado o diâmetro médio da colônia tomado no reverso das placas de Petri, através da medição em dois sentidos diametralmente opostos, e por comparação com o crescimento das colônias nas placas testemunhas, que receberam o meio de cultura sem tratamentos, foi calculado a Percentagem de Inibição do Crescimento micelial (P.I.C.), pela diferença entre o crescimento da testemunha e o crescimento do tratamento dividido pelo crescimento da testemunha, multiplicado por 100 (4), expressa pela fórmula:

\section{P. I. C. $=\frac{\text { crescimento testemunha }- \text { crescimento tratamento }}{\text { crescimento da testemunha }} \times 100$}

Na avaliação do efeito curativo do óleo essencial de Citronela sobre a podridão seca, cachos de videira cv. Itália adquiridos em mercado local na cidade de Maceió, foram desinfetados com hipoclorito de sódio $0,1 \%$ e mantidos em temperatura ambiente. Posteriormente foram inoculados com o patógeno, realizando-se ferimentos nas bagas com o uso de lâminas esterilizadas, direcionando-se, em seguida, jatos de suspensão de conídios a uma concentração $\left(10^{5}\right.$ conídios. $\left.\mathrm{mL}^{-1}\right)$, calibrada em câmara de Neubauuer. A suspensão foi preparada adicionando $10 \mathrm{~mL}$ de água destilada esterilizada (ADE) em uma placa Petri contendo o micélio puro do patógeno, realizou-se a raspagem com o auxílio de uma escova de cerdas macias, logo após o material foi filtrado em gaze dupla esterilizada. Foram pulverizadas para cada cacho, e, após 4 horas, foram aspergidas as soluções do óleo essencial de Citronela $(0,25 ; 0,5 ; 1,0 ; 1,5$ e 2,0\%), utilizando-se água destilada esterilizada como testemunha.
As pulverizações foram realizadas com jatos direcionados aos cachos, aplicando-se $10 \mathrm{~mL}$ da solução por cacho, utilizando-se a mesma metodologia para todos os tratamentos. Em seguida, os cachos foram dispostos sobre papel absorvente para retenção do excesso de umidade e secagem sob ventilação, posteriormente foram acondicionados em sacos plásticos e mantidos a $25 \pm 1{ }^{\circ} \mathrm{C} / 80-90 \%$ de umidade relativa (UR), por 48 horas (ambiente de câmara úmida), e avaliados após o período de seis dias (Ensaio 1).

Com o objetivo de avaliar o potencial do óleo essencial no controle preventivo, os cachos foram aspergidos com as soluções de óleo, nas mesmas concentrações e testemunha, e após 4 horas foram inoculados com o fungo L. theobromae (Ensaio 2).

No ensaio 2, os cachos também foram dispostos sobre papel absorvente para retenção do ex cesso de umidade e secagem sob ventilação, onde permaneceram a $25 \pm 1{ }^{\circ} \mathrm{C} / 85-95 \%$ UR até o momento da inoculação. Os cachos que haviam sido inoculados quatro horas depois do tratamento foram igualmente acondicionados em sacos plásticos e mantidos a $25 \pm 1{ }^{\circ} \mathrm{C} / 80-90 \%$ UR, por 48 horas e avaliados após um período de seis dias, quanto à incidência e severidade perante escala de notas proposta por Camili et al. (4) que variou no intervalo de 1 a 6, baseada na área da lesão, correspondendo, aproximadamente, a 2, 5, 10, 20, 30 e 50\% da área lesionada da baga, respectivamente. Os resultados expressos em índice de doença sendo calculado através da fórmula: ID $(\%)=\{[(\mathrm{n} 1 \mathrm{x} 1)+\ldots+(\mathrm{n} 6 \times 6)] \times(6 \times N)-1\} \times 100$, onde, $\mathrm{n} 1 \ldots 6=\mathrm{n}^{\circ}$ de bagas infectadas com a respectiva nota $\mathrm{e}=\mathrm{n}^{\circ}$ total de bagas inoculadas, adaptada para $L$. theobromae (3).

$\mathrm{O}$ delineamento experimental utilizado para cada ensaio foi o inteiramente casualizado, com seis tratamentos e cinco repetições. Os dados foram submetidos à análise de variância, teste $\mathrm{F}$, e quando os efeitos de tratamentos apresentarem diferença significativa $(\mathrm{P}<0,01)$ as médias foram comparadas por meio do teste de regressão.

De acordo com os dados apresentados na Tabela 1, o óleo de Citronela, em todas as concentrações, foi capaz de inibir em 100\% o crescimento micelial de L. theobromae in vitro.

Medice et al. (7), ao avaliar o efeito fungitóxico do óleo essencial de Citronela na alíquota de $0,5 \mathrm{~mL}$ observaram total inibição da germinação de urediniósporos do fungo Phakopsora pachyrhizi. Pereira et al. (10) observaram total inibição de Cercospora coffeicola utilizando o óleo essencial de Citronela ( $C$. nardus) a partir da concentração de $1000 \mu \mathrm{LL}^{-1}$ (7), corroborando com os dados apresentados neste trabalho.

A utilização de extrato bruto de $C$. nardus, não obteve efeito antimicrobiano sobre Botrytis cinerea, no entanto, na concentração de $6,25 \%$ do óleo essencial, observou efeito fungitóxico sobre a germinação de esporos de $B$. cinerea, demonstrando que os compostos antifúngicos sintetizados por $C$. nardus possam se concentrar no óleo essencial e estarem presentes em concentrações muito baixas no hidrolato (14).

Ao testar o efeito de alecrim-pimenta (Lippia sidoides) observou o controle de L. theobromae. Os autores conseguiram uma inibição do crescimento micelial em $100 \%$ testando extratos e óleo essencial

Tabela 1. Crescimento Micelial do fungo Lasiodiplodia theobromae em presença de óleo essencial de Citronela em diferentes concentrações.

\begin{tabular}{lcccccc}
\hline \multicolumn{7}{c}{ Crescimento Micelial* (cm) } \\
\hline Conc. (\%) & $0 \%$ & $0.25 \%$ & $0.5 \%$ & $1 \%$ & $1.5 \%$ & $2 \%$ \\
\hline & $9.0 \mathrm{a}$ & $0.0 \mathrm{~b}$ & $0.0 \mathrm{~b}$ & $0.0 \mathrm{~b}$ & $0.0 \mathrm{~b}$ & $0.0 \mathrm{~b}$
\end{tabular}

"Letras iguais não diferem significativamente no teste de Tukey a 5\%. 


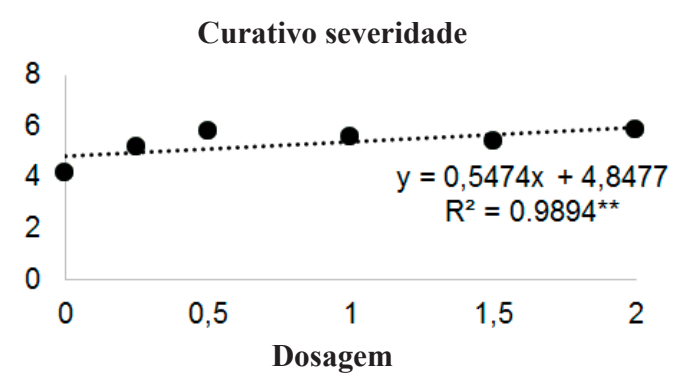

Preventivo severidade

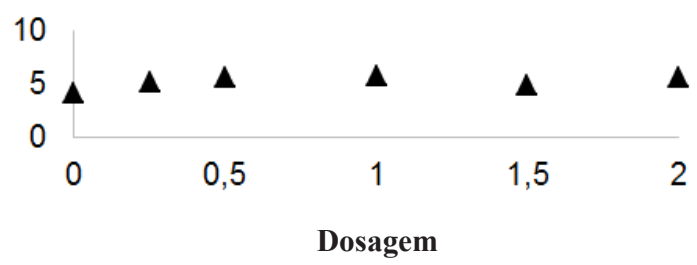

Curativo incidência

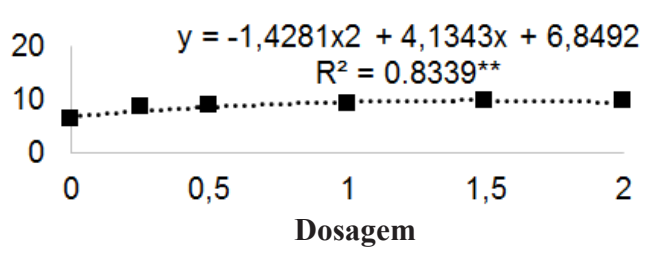

Preventivo incidência

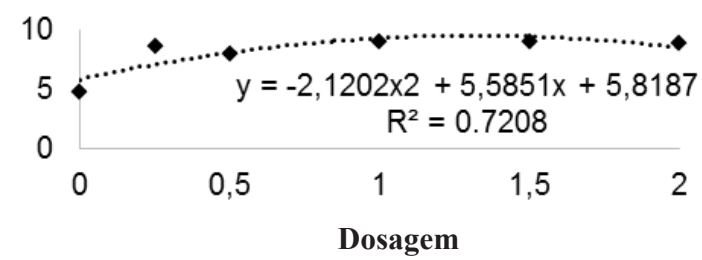

Figura 1. Óleo essencial de Citronela em diferentes concentrações no tratamento curativo e preventivo de Lasiodiplodia theobromae em cachos de uva cv. Itália avaliados no sexto dia após a inoculação.

obtidos de folhas de L. sidoides, o qual tem como constituinte principal o timol (8), divergindo do principal constituinte do óleo de citronela geraniol (9). Santos, et al. (11) testando o óleo de sementes de Schinus terebinthifolius verdes, o qual apresenta o limoneno em maior concentração, observou semelhanças de ação em ambos fitopatógenos estudados (C. gloeosporioides e L. theobromae), inibindo $100 \%$ do desenvolvimento na concentração de $3 \%$. Estes estudos mostram a importância da constituição dos óleos com efeitos similares de compostos diversos.

Autores relataram a eficiência dos monoterpenos presentes nos óleos de Cymbopogon citratus, C. nardus e Eucalyptus citriodora no controle in vitro dos fungos Colletotrichum gloeosporioides, C. musae e Fusarium subglutinans f. sp. ananás (1).

Seixas et al. (12) avaliaram o efeito de inibição do óleo essencial do capim-Citronela no crescimento micelial do fungo Fusarium subglutinans e verificaram que o óleo essencial teve maior efeito de inibição do crescimento micelial. Este maior efeito de inibição do óleo essencial está relacionado ao sinergismo existente entre os compostos do óleo essencial do Capim-Citronela, que atuam de forma conjunta, o que propiciou um maior efeito fungistático.

Os resultados relativos ao efeito do óleo essencial de Citronela, no tratamento preventivo e curativo, mediante a determinação da incidência e severidade da podridão seca ( $L$. theobromae) podem ser observados na Figura 1. Com relação a incidência no tratamento curativo, pode-se observar que apenas Citronela na concentração de $0,25 \%$ diferiu estatisticamente de todos os tratamentos, apresentando $62 \%$ bagas infectadas. Todos os outros tratamentos não apresentaram diferença estatística significativa em relação a testemunha, apresentando $96 \%$ de bagas infectadas. Em relação a severidade a concentração de $0,25 \%$ teve $44 \%$ da severidade da doença, diferindo estatisticamente da testemunha.

Com relação ao tratamento preventivo a incidência, foi possível observar que apenas o óleo de Citronela na concentração de $0,25 \%$ diferiu estatisticamente de todos os tratamentos, apresentando $48 \%$ bagas infectadas. Todos os outros tratamentos não apresentaram diferença estatística significativa em relação à testemunha, apresentando $88 \%$ de bagas infectadas. Em ralação a severidade o óleo de Citronela a $0,25 \%$ reduziu a severidade da doença apresentando $33,7 \%$ de índice de doença, diferindo significativamente da testemunha, $84 \%$ de índice de doença.

Óleos essenciais de erva-doce (Pimpinella anisum L.) e de Citronela (Cymbopogon nardus L.) têm sido avaliados com relação aos seus efeitos in vitro e in vivo sobre o desenvolvimento de fitopatógenos, vislumbrando-se assim possibilidades de uso desses produtos como método de controle alternativo para fins fitossanitários $(7,5)$.

O óleo de Citronela, em todas as concentrações testadas, foi capaz de inibir o crescimento micelial de L. theobromae em $100 \%$. No tratamento curativo, com relação a incidência, Citronela $0,25 \%$ reduziu $38 \%$ na infecção de bagas de cachos de uva inoculadas com L. theobromae, sendo capaz de reduzir a severidade da doença em $56 \%$. No tratamento preventivo, o óleo de Citronela a $0,25 \%$ reduziu em $52 \%$ a infecção das bagas de uva cv. Itália, reduzindo a severidade da doença em $66,3 \%$.

Com os resultados obtidos neste trabalho é possível concluir que a concentração $0,25 \%$ foi a melhor dosagem testada a ser utilizada no controle da doença com o óleo essencial de Citronela devido ao efeito fungitóxico e fungistático.

\section{REFERÊNCIAS}

1.Ventura, J., Santos, T., Alves, E., Pupo, M., Fernandes, P., Vilches, T., \& Marques, S. Avaliação de óleos essenciais na inibição do crescimento de fungos de fruteiras tropicais. Fitopatologia Brasileira, Uberlândia, v.28, n.Supl, p.343, 2003. (Resumos).

2.Amorim, L. C. A. Os biomarcadores e sua aplicação na avaliação da exposição aos agentes químicos ambientais. Revista Brasileira de Epidemiologia. v.6, n.2, p.158-170, jun. 2003.

3.Barguil, B. M., Oliveira, S. M. A., Coelho, R. S. B., \& Junior, J. E. A. B. Ocorrência de Colletotrichum gloeosporioides em Heliconia chartacea cv. Sex Pink. Fitopatologia Brasileira, Brasília, DF, v.30, p.S136. 2005.

4.Camili, E.C.; Benato, E.A.; Pascholati, S.F.; Cia, P. Avaliação de quitosana, aplicada em pós-colheita, na proteção de uva 'Itália' contra Botrytis cinerea. Summa Phytopathologica, Botucatu, v.33, p.3, p.215-221, 2007.

5.Costa, L.C. do B.; Pinto, J.E.B.P.; Castro, E.M. de; Bertolucci, S.K.V.; Corrêa, R.M.; Reis, É.S.; Alves, P.B.; Niculau, E. dos S. Tipos e doses de adubação orgânica no crescimento, no rendimento e na composição química 
do óleo essencial de elixir paregórico. Ciência Rural, Santa Maria, v.38, p.2173-2180, 2008.

6.Kimati, H.; Soave, J. Guia de fungicidas agrícolas: recomendações por cultura. 2.ed. Jaboticabal: Grupo Paulista de Fitopatologia, 1997. 225p.

7. Medice, R., Alves, E., Assis, R. D., Magno Júnior, R. G., \& Lopes, E. A. G. L. Óleos essenciais no controle da ferrugem asiática da soja Phakopsora pachyrhizi syd. \& p. Syd. Ciência e Agrotecnologia, Lavras, v.31, n.1, p.83-90, 2007.

8. Mota, J.C.O.; Pessoa, M.N.G.; Viana, F.M.P.; Andrade Neto, M. Efeito de extratos e óleos essenciais de plantas medicinais no controle in vitro de Lasiodiplodia theobromae. Fitopatologia Venezolana, Caracas, v.15, n.1, p.2-6, 2002.

9. Nakahara, K., Alzoreky, N. S., Yoshihashi, T., Nguyen, H. T., \& Trakoontivakorn, G. Chemical composition and antifungal activity of essential oil from Cymbopogon nardus (citronella grass). Japan Agricultural Research Quarterly: JARQ, Japão, v.37, n.4, p. 249-252, 2013.
10.Pereira, R. B., Lucas, G. C., Perina, F. J., Resende, M. L. V. D., \& Alves, E. Potential of essential oils for the control of Brown eye spot in coffee plants. Ciência e Agrotecnologia, Lavras, v.35, n.1, p.115-23, 2011.

11. Santos, I.T.B.F.; Santos, T.S.; Silva, F.L.S; Gagliardi, P.R. Óleo essencial de Schinus terebinthifolius Raddi como controle alternativo de Colletothrichum gloeosporioides e Lasiodiplodia theobromae, fungos fitopatogênicos de póscolheita. Revista GEINTEC, São Cristóvão, v.4, n.4, p.1409-1417, 2014

12. Seixas, P.T.L.; Castro, H.C.; Santos, G.R.; Cardoso, D.P. Controle fitopatológico do Fusarium subglutinans pelo óleo essencial do Capim-Citronela (Cymbopogon nardus L.) e do composto citronelal. Revista Brasileira de Plantas Medicinais, Botucatu, v.13. p.523-526, 2011.

13. Tavares, S.C.C.H. Epidemiologia e manejo integrado de Botryodiplodia theobromae - situação atual no Brasil e no mundo. Fitopatologia Brasileira, Brasília, DF, v.27, p.46-52, 2002.

14. Wilson, C.L.; Solar, J.M.; El Ghaouth, A.; Wisniewski, M.E. Rapid evaluation of plant extracts and essential oils for antifungal activity against Botrytis cinerea. Plant Disease, Saint Paul, v.81, p.204-210, 1997. 